\title{
Utilizing Silica from Rice Hull for the Hydrothermal Synthesis of Zeolite Y
}

\author{
Yasmin D.G. Edañol ${ }^{1}$, Ken Aldren S. Usman ${ }^{2,3}$, Salvador C. Buenviaje, Jr. ${ }^{1}$ Michael E. Mantua ${ }^{3}$ \\ and Leon M. Payawan, $\mathrm{Jr}^{3}{ }^{*}$ \\ ${ }^{1}$ Materials Science and Engineering Program, College of Science, University of the Philippines - Diliman, \\ Quezon City \\ ${ }^{2}$ Natural Sciences Research Institute, College of Science, University of the Philippines - Diliman, Quezon City \\ ${ }^{3}$ Institute of Chemistry, College of Science, University of the Philippines - Diliman, Quezon City
}

\begin{abstract}
Rice hull, a known agricultural waste product, with $21 \%$ silica $\left(\mathrm{SiO}_{2}\right)$ content based on elemental analysis, is a promising starting material for zeolite $\mathrm{Y}$ synthesis. In this work, silica derived from rice hull samples were extracted via alkaline treatment using $4 \mathrm{M} \mathrm{NaOH}$ at $130^{\circ} \mathrm{C}-150^{\circ} \mathrm{C}$. Further introduction of $\mathrm{NaOH}$ and inclusion of aluminium hydroxide were done before subjecting the materials to subsequent ageing and heating at $95{ }^{\circ} \mathrm{C}$ to form the zeolite $\mathrm{Y}$ crystals. The samples were then analyzed using Fourier transform infrared spectroscopy (FT-IR) and X-ray diffractometry (XRD). Zeolite Y from commercial silica was also synthesized as negative control and together with commercially available zeolite Y, FT-IR and XRD results showed that they possess similar structures with the rice-hull derived material.
\end{abstract}

Keywords: rice hull; silica; zeolite Y; XRD; FT-IR

\section{INTRODUCTION}

According to a report by the Philippine Statistics Authority (PSA), the Philippines produced 19.28 million metric tonnes (MT) of rice in 2017. This is 1.65 million MT or $9.36 \%$ more than the 17.63 million MT produced in 2016. The higher production resulted in a 2.7 million MT surplus in rice supply which is expected to rise up to 3 million MT (Lomibao, 2008; Special Release, 2012). The increased rice production also results in the increased volume of rice hulls. Rice hulls are agricultural residues abundant in rice-producing countries, such as the Philippines. Rice hulls contain 20\% silica, $38 \%$ cellulose, $22 \%$ lignin, $18 \%$ pentose, and $2 \%$ other organic components (Adam, et al., 2012). Some of these rice hulls are converted into useful products such as compost, adsorbents and precursor for activated carbons (Adam et al., 2012; Hieu et al., 2015; Basta et al., 2009). However, most of the rice hulls are burnt in open air, causing health and environmental problems by producing aerosol particles that affect air quality (Basta et al., 2009). Furthermore, its potential use as food for livestock is an economic use. The high fibre and silica content also limits its use as food because it is degraded slowly in ruminant animals. Slow degradation of rice hulls affects the energy intake of ruminant animals which can ultimately affect their productivity (Abou-El-Enin et al., 1999; Friedman, 2013). Also, other competitive resources are available for the aforementioned applications, thus, the use of rice hull is still minor (Basta et al., 2009). Therefore, finding other ways to utilize rice hulls are of utmost importance.

Silica, $\mathrm{SiO}_{2}$, is a primary component of rice hulls, accounting for $20 \%$ of its mass. Over the years, 
researchers have utilized rice hulls to prepare zeolites and mesoporous $\mathrm{SiO}_{2}$ (An et al., 2010). Zeolites are crystalline solids that contain channels and cages of molecular dimensions that allow entry of other molecules (Trinidad et al., 2016). These crystalline solids are composed of three-dimensional networks of silicon and aluminum oxide tetrahedrons $\left(\mathrm{SiO}_{4}\right.$ and $\mathrm{AlO}_{4}^{-}$) linked by shared oxygen atoms (Garcia et al., 2016). Elements of group IA and IIA such as sodium, potassium, magnesium, and calcium comprise crystalline aluminosilicate zeolites. These cations balance the negative charge that the $\mathrm{AlO}_{4}$ tetrahedron carries. The empirical formula for zeolites is $\mathrm{M}_{2 / \mathrm{n}} \mathrm{O} \cdot \mathrm{Al}_{2} \mathrm{O}_{3} \cdot y \mathrm{SiO}_{2} \cdot w \mathrm{H}_{2} \mathrm{O}$, in which $n$ corresponds to the valence electrons of the cations, $y$ 's value is $2-200$, and $w$ is the water trapped in the channels of zeolite cages (Johnson et al., 2014).

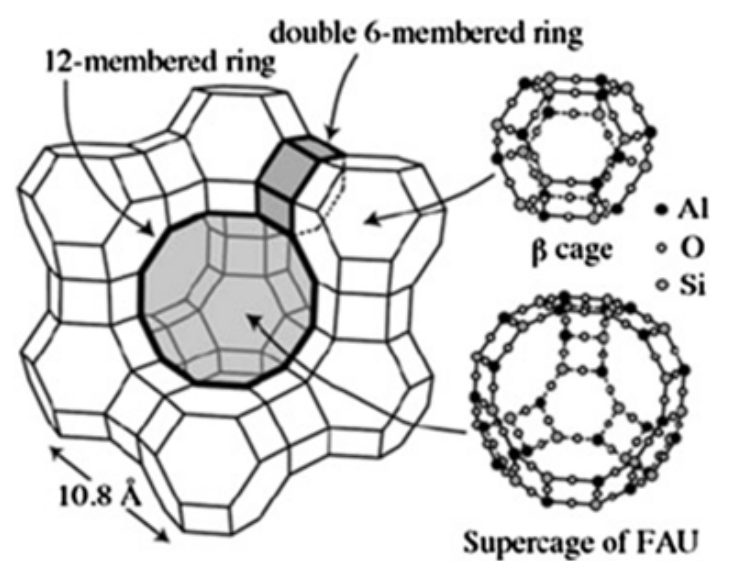

Figure 1. Framework Structure of Faujasite-type Zeolites.

Zeolites $\mathrm{X}$ and $\mathrm{Y}$ are two zeolites of similar structure and of particular interest. Zeolites $\mathrm{X}$ and $\mathrm{Y}$ are faujasite type zeolite (FAU) in which the $\mathrm{SiO}_{2} /$ $\mathrm{Al}_{2} \mathrm{O}_{3}$ for zeolite $\mathrm{Y}$ is greater than three (Garcia et al., 2016). Figure 1 shows the framework structure of faujasite zeolites. It consists of two cages: the $\alpha$-cage (supercage) and the $\beta$-cage (sodalite cage). The sodalite cages are linked to one another via hexagonal prisms and the pores of FAU-type zeolites are formed by a 12-membered ring (Johnson et al., 2014). The porous nature of zeolites made them useful in various applications such as ion exchange, adsorption, catalysis, and membrane separation (Garcia et al., 2016). In addition, the presence of aluminum atoms in the framework induces the acidic properties of zeolites, making them good solidacid catalysts. Petroleum industries utilize zeolites as catalysts for heavy hydrocarbon cracking (Anis et al., 2016). Ninety-five percent of fluid catalytic cracking (FCC) units rely on FAU-type zeolites such as zeolites $\mathrm{X}$ and $\mathrm{Y}$ (Anis et al., 2016; Vermeiren and Gilson, 2009). Processes such as Methanol to Gasoline (MTG) and Methanol to Olefins (MTO) conversions uses MFI-type and CHA-type zeolite as catalysts, respectively. The catalytic application of zeolites also found their way in the synthesis of pharmaceutical drugs and other fine chemicals (Liu et al., 2016).

In this work, silica was extracted from rice hull and was used as a starting material for the synthesis of zeolite $\mathrm{Y}$ via the hydrothermal method. The synthetic zeolite $\mathrm{Y}$ was characterized using Fouriertransform infrared spectroscopy (FT-IR) and $\mathrm{x}$-ray diffractometry (XRD).

\section{METHODOLOGY}

Materials and Equipment. Aluminum hydroxide (Sigma-Aldrich), sodium hydroxide (Merck), sodium silica solution (Code:001394), zeolite Y (Sigma), and potassium bromide (Sigma-Aldrich) were used as-received. A Memmert oven was used for the ageing and drying processes. An FTS-40A BioRad FT-IR spectrophotometer was used for the spectroscopic analysis. An Xpert Powder X-ray diffractometer was used for the structure analysis of the zeolite.

Extraction of Silica from Rice Hull. Rice hull samples were collected from the Bureau of Animal Industry. Samples of rice hull were sent to SGS Philippines, Inc for elemental analysis. The rice hulls were used without any pre-treatments prior to extraction. Rice hull samples $(2.90 \mathrm{~g})$ were added to $30 \mathrm{ml}$ of $4 \mathrm{M} \mathrm{NaOH}$ solution in a poly (tetrafluoroethylene) bottle. The mixture was subjected to heating at $130-150{ }^{\circ} \mathrm{C}$ for 24 hours, accompanied by periodic addition of water to maintain its initial volume. Without cooling, the hot solution was subsequently filtered using a filter paper through a plastic funnel. The filtrate is then cooled to room temperature for zeolite $Y$ synthesis.

Synthesis of Zeolite Y from Rice hull-derived and Commercially Available Silica Sources. Sodium hydroxide $(2.16 \mathrm{~g})$ was dissolved in deionized water in a poly (tetrafluoroethylene) bottle. Aluminum hydroxide $(1.25 \mathrm{~g})$ was then added and the bottle was shaken until all aluminum hydroxide were dissolved completely. To the resulting solution, 20 $\mathrm{g}$ of $30 \%$ rice-hull derived silica solution was added, followed by an ageing process for 24 hours at room temperature. Subsequent heating of the solution to $95^{\circ} \mathrm{C}$ without stirring was done for 72 hours. The product was filtered, washed with deionized water until the $\mathrm{pH}$ of the washings was below 9, cooled to room temperature, and air-dried. The product was then subjected to $\mathrm{x}$-ray diffractometry (XRD) and Fourier-transform infrared spectroscopy (FT-IR). A similar set up was also done but using commerciallyavailable silica instead of the extracted silica. 


\section{RESULTS AND DISCUSSION}

Extraction of Silica from Rice Hull. Rice hull samples were sent to SGS Philippines, Inc. for elemental analysis. The elemental analysis revealed that the samples contain $21 \% \quad \mathrm{SiO}_{2}$. Alkaline treatment using $4.0 \mathrm{M} \mathrm{NaOH}$ at temperature of $130-150{ }^{\circ} \mathrm{C}$ for 24 hours was done in order to dissolve and convert $\mathrm{SiO}_{2}$ into a viscous and transparent solution consisting of $\mathrm{Na}_{2} \mathrm{SiO}_{3}$ as shown in Equation 1 (Todkar et al., 2016; Yuvakkumar et al., 2014).

$$
\mathrm{SiO}_{2}+2 \mathrm{NaOH} \rightarrow \mathrm{Na}_{2} \mathrm{SiO}_{3}+\mathrm{H}_{2} \mathrm{O}
$$

The resulting silica-rich extract was separated from the crude rice hull samples via hot filtration. This process parts the silica form other water-insoluble materials such as lignin and cellulose that were also present in the crude samples. Lignin solubility in aqueous solution is limited due to its hydrophobicity, but it dissolves to some extent in alkaline solution. However, the periodic addition of water decreased the alkalinity of the solution, causing lignin to precipitate out and be separated in the filtration step (Evstigneev, 2011). Cellulose was found to be soluble in aqueous $\mathrm{NaOH}$ only by freezing it to -20 ${ }^{\circ} \mathrm{C}$ followed by thawing to room temperature. The high temperature conditions of the method ensured that cellulose remain undissolved in the extraction step. Thus, it is also separated during the filtration step (Isogai and Atalla, 2011).

Synthesis of Zeolite from Rice Hull-derived and
Commercially Available Silica Sources. The resulting $\mathrm{Na}_{2} \mathrm{SiO}_{3}$ solution was then utilized as the silica-source for the conventional hydrothermal Zeolite Y synthesis. A previous study by (Rahman et al., 2009) also used the hydrothermal technique for Zeolite $\mathrm{Y}$ synthesis. The silica solution, together with $\mathrm{NaOH}, \mathrm{H}_{2} \mathrm{O}$ and alumina $\left(\mathrm{Al}_{2} \mathrm{O}_{3}\right)$, are the building blocks for zeolite $\mathrm{Y}$. The $\mathrm{Al}_{2} \mathrm{O}_{3}$ molecules are converted to aluminate ions which links to oligomeric silica molecules, forming and the excess ions remain in solution. During the ageing process, the gel consumes more aluminate, forming the three-dimensional structure of zeolite Y. The 3D structure is stable at room temperature and the negatively charges inside the zeolite $\mathrm{Y}$ prevents further inclusion of other negatively charged ions such as $\mathrm{OH}^{-}$. Hydroxide ions are further eliminated from the mixture by reducing the $\mathrm{pH}$ below 9 (Lutz, 2014).

Fourier-Transform Infrared Spectroscopy (FTIR). FT-IR was used to deduce structural information for the zeolite samples. However, only the mid-infrared region $\left(1300-200 \mathrm{~cm}^{-1}\right)$ was used to investigate the framework of synthetic zeolites. It contains the fundamental vibrations of $\mathrm{TO}_{4}(\mathrm{~T}=\mathrm{Al}, \mathrm{Si})$ tetrahedra. Two types of vibration can be observed from zeolite structures: internal $\mathrm{TO}_{4}$ tetrahedrons and vibrations due to linkages (de Araujo et al., 1999). The FTIR spectra for the commercially available zeolite Y, synthesized zeolite from commercial silica and rice hull-derived silica are shown in Figures 2, 3 and 4.

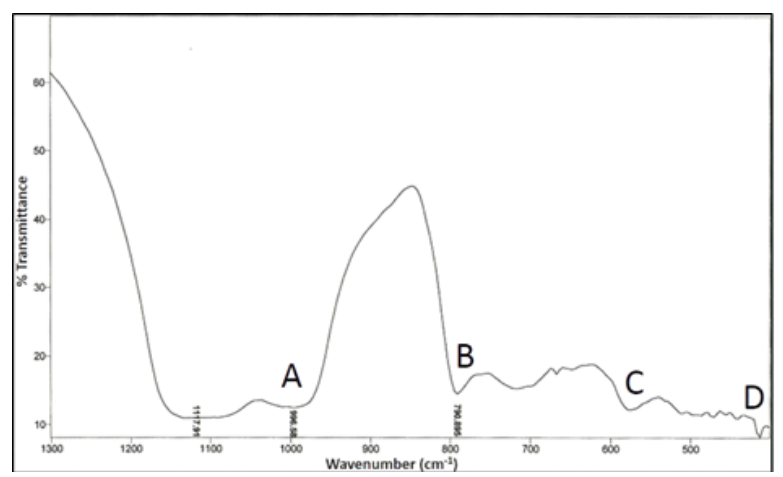

Figure 2. FT-IR Spectra of Commercially Available Zeolite $Y$.

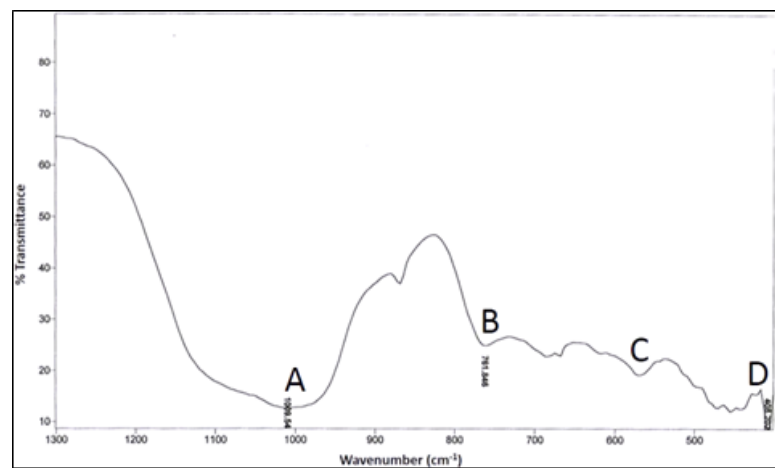

Figure 3. FT-IR Spectra of Zeolite Y from Commercial Silica.

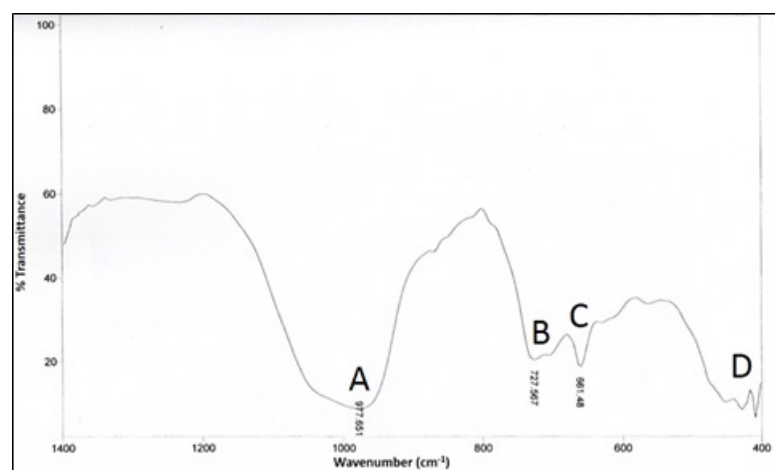

Figure 4. FT-IR Spectra of Zeolite Y from Rice Hullderived Silica.

From the FT-IR spectra presented in Fig. 2-4, it can be seen that there are four characteristic vibrations common on all three samples analyzed. Peaks A, observed at $-1000 \mathrm{~cm}^{-1}$, is the strongest vibration found in all zeolites. These vibrations are attributed to the internal tetrahedron vibrations of zeolites. Peak $\mathrm{B}$, observed at $-800-700 \mathrm{~cm}^{-1}$, is the stretch assigned 
to the tetrahedral atoms, which are sensitive to Si$\mathrm{Al}$ composition of the network. This stretch shifts to lower frequencies as the number of tetrahedral $\mathrm{Al}$ atoms increases. Peak C, observed at $-680-550$ $\mathrm{cm}^{-1}$, is due to the presence of double rings in the framework structures. This peak is observed for all zeolites having the same structure. Peak D, observed at $-500-400 \mathrm{~cm}^{-1}$, is also a characteristic vibration of the internal tetrahedrons of zeolite structures (de Araujo et al., 1999; Flanigen et al., 1971).

The appearance of the same peaks for all samples suggest that the framework of the samples are similar to those of previously studied zeolites. In order to further confirm this assumption, the samples were subjected to XRD analysis.

$X$-ray Diffractometry (XRD). The structural framework of the zeolite samples were further studied using XRD. The obtained XRD pattern for the commercially available and synthesized zeolite $y$ samples are shown in Figure 5. The presence of sharp peaks indicate that the samples analyzed exhibit crystallinity. The crystalline structure observed from the XRD patterns of the samples are comparable to the standard XRD pattern of faujasite - type cubic zeolite Y from the "Collection of Simulated XRD Powder Patterns for Zeolites" (Treacy and Higgins, 2007). Previous studies done by Wittayakun et al. (2014), Paragas et al. (2014), and Rosman et al. (2014) also exhibit the same XRD pattern. Thus, it can be concluded that the synthetic zeolites are indeed zeolite Y's of faujasite - type cubic lattice. Furthermore, the narrow width of the peaks reveal that the zeolite Y's have a small crystallite size (Flanigen EM et al., 1971).

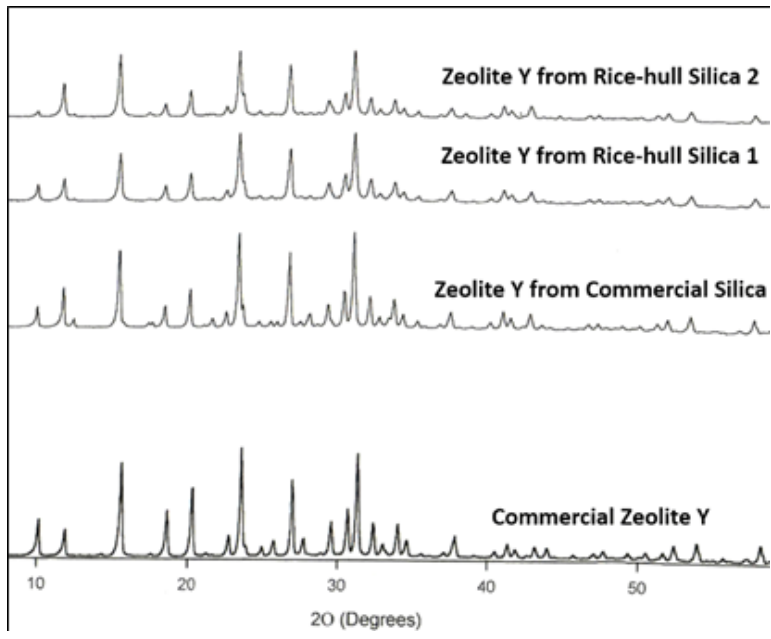

Figure 5. X-Ray Diffractogram for All Samples.

\section{CONCLUSION}

Dissolution of rice hulls in alkaline media yielded silica that was used in the hydrothermal synthesis of zeolite Y. FT-IR and XRD analyses confirmed that the structural framework of the synthetic zeolite Y's are the same in previously studied zeolite Y's. XRD also confirmed that the synthetic products are of the faujasite-type cubic zeolite Y's. The simple extraction method performed in the study reveal that rice hulls can be fully utilized as silica sources. This result not only lessens environmental concerns about rice hulls, it also increases the availability of an important raw material. Therefore, rice hull can be a viable source of silica. Furthermore, this study reveals an alternative and cheaper method for the synthesis of zeolites that can be used for a wide variety of applications.

\section{REFERENCES}

Abou-El-Enin OH, Fadel JG, Mackill DJ. Differences in chemical composition and fibre digestion of rice straw with, and without, anhydrous ammonia from 53 rice varieties. Anim Sci Technol. 1999; 79(1): 129-136.

Adam F, Appaturi JN, Iqbal A. The utilization of rice husk silica as a catalyst: review and recent progress. Catal Today. 2012; 190(1): 12-14.

An D, Guo Y, Zhu Y, Wang Z. A green route to preparation of silica powders with rice husk ash and waste gas. Chem Eng J. 2010; 162(2): 509-514.

Anis SF, Khalil A, Saepurahman, Singaravel G, Hashaikeh R. A review on the fabrication of zeolite and mesoporous inorganic nanofibers formation for catalytic applications. Microporous and Mesoporous Mater. 2016; 236: 176-192.

Basta, AH, Fierro V, El-Saied H, Celzard A. 2-Steps $\mathrm{KOH}$ activation of rice straw: an efficient method for preparing high-performance activated carbons. Bioresour Technol. 2009; 100(17): 3941-3947.

de Araujo LRG, Cavalcante CL, Farias KM, Guedes I, Sasaki JM, Freire PTC et al. Synthesis of cubic Y zeolite using a pulsed microwave heating system. Mater Res. 1999; 2(2): 105-109.

Evstigneev EI. Factors affecting lignin solubility. Russ J Appl Chem. 2011; 84(6): 1040-1045.

Flanigen EM, Khatami H, Szymanski HA. Infrared structural studies of zeolite frameworks. Adv Chem. 1971: 201-229.

Friedman M. Rice brans, rice bran oils, and rice hulls: composition, food and industrial uses, and bioactivities in humans, animals, and cells. J Agric Food Chem. 2013; 61(45): 10626-10641. 
Garcia G, Cardenas E, Cabrera S, Hedlund J, Mouzon J. Synthesis of zeolite Y from diatomite as silica source. Microporous and Mesoporous Mater. 2016; 219: 29-37.

Hieu NM, Korobochkin VV, Tu NV. A study of silica separation in the production of activated carbon from rice husk in Viet Nam. Procedia Chem. 2015; 15: 308-312.

Isogai A, Atalla RH. Dissolution of cellulose in aqueous $\mathrm{NaOH}$ solutions. Cellulose. 1998; 5(4): 309-319.

Johnson EBG, Arshad SE. Hydrothermally synthesized zeolites based on kaolinite: a review. Appl Clay Sci. 2014; 97: 215-221.

Liu Z, Shi C, Wu D, He S, Ren B. A simple method of preparation of high silica zeolite $\mathrm{Y}$ and its performance in the catalytic cracking of cumene. J Nanotechnol. 2016; 2016: 1-6.

Lomibao W. (2018, February 08). Rice production up by 1.65 million tons in 2017 - gov't data. Philippine Daily Inquirer. Retrieved from: http:// www.newsinfo.inquirer.net

Lutz, Wolfgang. Zeolite Y: Synthesis, modification, and properties-A case revisited. Adv Mater Sci Eng. 2014; 2014: 1-20.

Paragas DS, Salazar JR, Ginez MO. Preparation, Characterization and Application of Rice Hullderived Zeolites in Water Treatment. J Asian Sci Res. 2014; 4(7): 348-355.

Rahman MM, Hasnida N, Wan Nik WB. Preparation of Zeolite Y Using Local Raw Material Rice Husk as a Silica Source. J Sci Res. 2009; 1(2): 285-291.

Rosman N, Harun Z, Wahab MSB, Hubadillah, SK, Aminudin NN. Phase Transformation of Rice Husk Ash in the Synthesis of NaY Zeolite: Effect of ageing in short crystalline duration. Aust J Basic Appl Sci. 2014; 8(15): 152-159.

Special Release (2018, January 22). Rice and Corn Situation Outlook, January 2018 Round. Philippine Statistics Authority. Retrieved from: http://www. psa.gov.ph

Todkar BS, Deorukhkar OA, Deshmukh SM. Extraction of silica from rice husk. Int J Eng Res Dev. 2016; 12: 69-74.

Treacy MMJ, Higgins JB. Collection of simulated
XRD powder patterns for zeolites fifth (5th) revised edition. Elsevier; 2007.

Trinidad LJPL, Arguilla MQ, Usman KAS, Payawan LMP. "Ship-in-a-Bottle" Synthesis of Fluorescent Iridium (III) Complex Ion unto Zeolite Y Supercages. Key Eng Mater. 2016; 707: 135-138.

Vermeiren W, Gilson JP. Impact of zeolites on the petroleum and petrochemical industry. Topics in Catalysis. 2009; 52(9): 1131-1161.

Wittayakun J, Khemthong P, Prayoonpokarach S. Synthesis and characterization of zeolite $\mathrm{NaY}$ from rice husk silica. Korean J Chem Eng. 2008; 25(4): 861-864.

Yuvakkumar R, Elango V, Rajendran V, Kannan N. High-purity nano silica powder from rice husk using a simple chemical method. J Exp Nanosci. 2014; 9(3): 272-281. 